\title{
Progressive development of avoidance response after training, ECS, and repeated testing*
}

\author{
SUSAN J. SARA \\ Lniversitr of Louvain. Lourain, Belgium
}

Wistar rats were given one-trial passive avoidance training followed by ECS or sham ECS. They were repeatedly tested at $24-\mathrm{h}$ intervals for a total of five test sessions of $3 \mathrm{~min}$ each. At $24 \mathrm{~h}$, the sham ECS group showed avoidance behavior while the ECS group failed to avoid the shock compartment. The sham ECS group continued to avoid throughout the five testing sessions. The ECS group showed avoidance behavior at 72,96 , and $120 \mathrm{~h}$. There were no significant differences at these times between ECS and sham ECS. Systematic control groups receiving no footshock on noncontingent footshock never developed avoidance behavior. These groups were not different from the ECS group at 24 and $48 \mathrm{~h}$, and were significantly different from the ECS group at 96 and $120 \mathrm{~h}$. Since the effects of ECS were shown to be temporary, the results are taken to indicate that ECS acts on retrievability of memory rather than on memory storage.

The body of literature showing recovery from experimental amnesia continues to grow. Most of the studies producing recovery have used a footshock (FS) as a reminder (e.g.. Miller \& Springer. 1972; Ouartermain et al. 1970), but Springer \& Miller (1972) have recently demonstrated that a stressful event dissimilar to the negative training reinforcement can equally reinstate avoidance behavior. Quartermain et al (1970) were able to produce a recovery from amnesia only if an exposure to the training environment preceded the FS reminder. This group noted, furthermore, that most-but not all-positive studies of the reminder effect included this exposure in the procedure, while most negative studies did not. Later experiments by Quartermain's group (1972) and by Sara (1973) indicate that under certain circumstances. a single exposure to the training environment. in which the animal enters the shock compartment but receives no FS, is sufficient to produce avoidance behavior on a subsequent test.

Contrary to the report of Springer \& Miller (1972), preliminary studies in the Pellenberg laboratory indicate that the temporal relation between the reminder event and the test in which recovery is shown is important. Previous studies have shown that a rat which behaves "amnestically" $24 \mathrm{~h}$ after ECS will recover if replaced in the experimental apparatus $5 \mathrm{~min}$ after the first test. in spite of the fact that the first test gave the opportunity for extinction of any tendency to avoid the small compartment. The same phenomenon has been observed

* This work was supported by Grant 921 of the Fonds de la Recherche Fondamentale Collective. Requests for reprints should be sent to Susan J. Sara. Center for Experimental and Comparative Psychology. Cháteau de \& à B - 3041 - Pellenberg. Belgium. The article is sponsored by Norman Spear, who takes full editorial responsibility for its contents. with a $30-\mathrm{min}$ lapse between the two tests in rats having exhibited amnestic behavior induced by hypoxia (Sara, 1973). However, if the time between the reminder test and retest is $24 \mathrm{~h}$, with ECS as the amnestic agent, there is no recovery seen at retest (Sara, unpublished results). This has also been observed by Quartermain (1972). The present experiment examines the possibility that tests repeated at 24 -h intervals could restore memory.

\section{METHOD \\ Animals}

Male Wistar rats, weighing $150-200 \mathrm{~g}$ were obtained from Linion Chimique Belge. They were housed in groups. 8-10 to a cage. and were allowed free access to food and water. Several days of habituation to the laboratory conditions were allot ted before the first day of the experiment.

\section{Apparatus}

The training apparatus was the same as that described in other reports from this laboratory (Sara, 1973). The large. unshocked compartment was painted flat white, was illuminated with a $100-W$ bulb, and measured $30 \times 30 \times 30 \mathrm{~cm}$. The aluminum floor was covered with gravel. the same as in the living cages. The small shock compartment was painted black and measured $10 \mathrm{x}$ $10 \times 10 \mathrm{~cm}$. The floor was made of metal rods. $12 \mathrm{~mm}$ apart. through which a FS could be delivered. The shock source was a $700-\mathrm{V}, 50-\mathrm{Hz}$ transformer; the shock was delivered through a Foringer shock scrambler. The shock level was approximately $1 \mathrm{~mA}$. The two compartments were separated by a guillotine door $6 \times 6 \mathrm{~cm}$. Noncontingent footshock (NCFS) was administered in a Plexiglas box in a separate room, using the same shock generator and grid floor as in the training apparatus. The ECS was administered by means of electrodes manually: applied to the temples of the rats. just between the eye and the ear. The shock source was a $1.200-\mathrm{V}$ transformer with a $10 \mathrm{~K} \mathrm{ohm}$ series resistence. The output was $50 \mathrm{~mA}$ for $350 \mathrm{msec}$.

\section{Procedure}

The animals were divided into six groups. The training procedure consisted of placing the rat in the corner of the large compartment facing away from the opening to the dark compartment. One minute of free exploration of both compartments was permitted: the latency to enter the dark compartment and the total time spent in the small compartment were noted for each animal. At the end of the exploration period. the door was lowered and a 5 -sec FS was administered. (It should be noted that in almost all cases, the rat was in the small compartment at the end of the exploration period. In a few exceptional cases. the exploration period was extended until the rat reentered the dark: in no case did this exceed 10 sec.) The animal was removed from the small compartment after FS and received either ECS (Group FS-ECS. $N=15$ ) or pseudo-ECS (Group FS. $N=9$ ). which entailed restraining the rat and applying the electrodes without current. The time between FS and ECS was recorded and never exceeded $10 \mathrm{sec}($ mean $=9$ ). The control animals that received no FS were simply confined in the small compartment for $5 \mathrm{sec}$ and then removed for ECS (Group ECS. $N=10$ ) or pseudo-ECS (Group 00. $N=9$ ). Two groups of animals received a noncontingent FS (NCFS) in a neutral environment $1 \mathrm{~h}$ before they were exposed to the training apparatus on the first day. One of these NCFS groups also had ECS within $10 \mathrm{sec}$ after the NCFS (Group NCFS-ECS. $X=9$ ). Those groups receiving FS in the training cage were 
exposed to the NCIS environment without is $1 \mathrm{~h}$ before training for a 30 -sec period.

The testing procedure consisted of placing the animal in the large compartment in the same manner as on the training day and noting the latency to enter the dark and the total time spent in each compartment for $3 \mathrm{~min}$. This procedure was repeated every day for 5 days at the same hour. I or the NCl:S and NCFS-LCS groups, the grid floor of the training apparatus was removed for all sessions. including the first day of exposure without I:S.

\section{RESULTS}

Figure 1 indicates the median total time in the small dark compartment for each group at each testing time. Lack of normal distribution of the results indicated a nonparametric statistical analysis. A Kruskal-Wallis one-way analysis of variance showed no difference among all groups before training as to the total time spent in the dark. The same analysis was made for the four systematic control groups at each time (Groups 00. NCFS, ECS, and NCFS-ECS): at no point was there a difference among these groups. The experimental (FS-ECS) and control (FS) groups were compared by a Mann-Whitney U test at each time, as were the NCFS-ECS and FS-ECS groups. At $24 \mathrm{~h}$, the difference between FS and FS-ECS was significant $(\mathrm{U}=14$, $\mathrm{p}<.002)$ : between NCFS-ECS and FS-ECS there was no difference $(U=48, p>.10)$, thus indicating that ECS treatment prevented the animal from making the adaptive avoidance response demonstrated by the FS group. At $48 \mathrm{~h}$, the difference between FS and FS-ECS groups was again significant $(U=31, p<.05)$ and the difference between NCFS-ECS and FS-ECS was not significant $(U=47, p>.10)$. At $72 \mathrm{~h}$, the differences between FS and FS-ECS and between NCFS-ECS and FS.ECS were not quite significant $(\mathrm{U}=35$. $.10>p>.05$ for each). At $96 \mathrm{~h}$, there is no difference between FS-ECS and FS $(U=53, p>.10)$, while the difference between NCFS-ECS and FS-ECS is significant $(\mathrm{U}=24, \mathrm{p}<.02)$. At $120 \mathrm{~h}$, these relations remain the same: FS-ECS is different from NCFS-ECS $(\mathrm{U}=33$. $p<.05)$ and does not differ from FS $(U=41 . p>.10)$.

\section{DISCUSSION}

These results clearly indicate that memory disrupted by ECS can be restored by repeated exposure to the training environment. The results are in agreement with those of Zinkin \& Miller (1967) and of Quartermain et al (1972). who found recovery of memory on the third exposure to the training environment if there was no reminder $\mathrm{HS}$. and on the second exposure if there was a ISS between the first and second exposures. The present experiment adds two control groups not included by Quartermain et al. the 00 group. which received no treatment at all. but repeated exposure to the training environment. and the NCIS group. which received only noncontingent $\mathrm{IS}$ and no $\mathrm{ECS}$. thus assuring that the avoidance behavior which develops gradually for the IS-ICS group is not due to an acquired aversion to the small compartment from which the animal is removed each time. It is interesting to note that during preliminary experiments. there was a reliable tendency for NCIS and NCIS-ICS animals to develop the same aroidance behavior. but more slowly than the I:S-LC'S group.

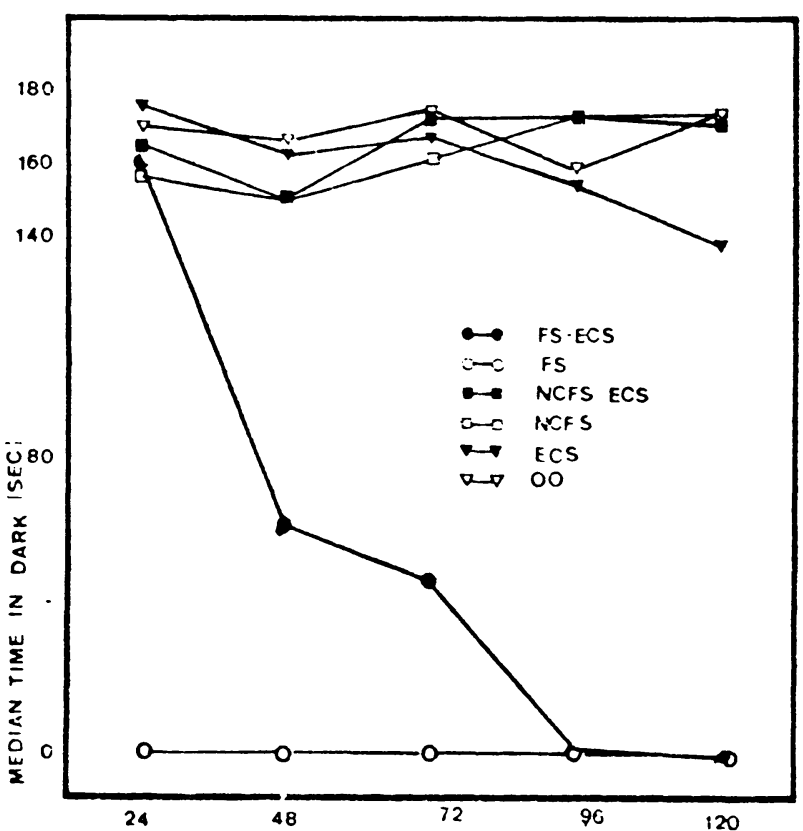

Fig. 1. Median total time in shocked compartment. The same animals are tested and retested at 24-h intervals. Note the gradual development of the appropriate avoidance response of Group FS-ECS.

The NCFS was delivered in a totally different environment, but the grid floor was the same as in the training-testing cage. Since the animals were housed in breeding cages with gravel floors. this was the first exposure to this type of floor. It was suspected that the grid floor of the small compartment acted as a "reminder" of the FS received in the neutral environment and that the small compartment gradually took on the aversive qualities associated with F. The large unshocked compartment had a gravel floor. When the experiment was run with the grid floor absent from the small compartment, both pre- and posttrial for the NCFS and NCFS-ECS groups. as was the case for those groups reported in the present experiment, no such tendency to develop avoidance of the small compartment was noted (see Fig. 1).

Cherkin $(1970,1972)$ has proposed that the recovery phenomenon can be explained by the fact that the animal receives new information during the reminder treatment. This new information is incorporated into the "subthreshold engram" that remains after the amnestic treatment. The resultant engram causes the behavioral change seen as recovery from amnesia. The new information presumably compensates for the information that was not consolidated or stored after the training session due to the amnestic treatment. The present results would not support such an interpretation. because the new information that is received during each testing trial. i.e.. no shock in the small compartment, is contrary to the original learning experience, i.e.. small compartment $=$ shock. Each trial lasts for $3 \mathrm{~min}$. and there are a total of five postshock trials. so if the animal were acting on newly acquired information. one would predict extinction of any avoidance tendencies rather than an increased tendency to avoid. Such a result demands an interpretation in terms of a recovery of already existing memory of $\mathrm{FS}$ in the small compartment.

\section{REFERENCES}

Cherkin. A. Retrograde amnesia: Impaired memory consolidation or impaired retrieval? Communications in Behavioral Biology. 1970,5.183-190. 
Cherkin, A. Retrograde amnesia in the chick: Resistance to the reminder effect. Physiology \& Behavior $1972,8,949-955$.

Miller, R. R., \& Springer, A. D. Induced recovery of memory in rats following electroconvulsive shock. Physiology \& Behavior, $1972,8,645-651$

Quartermain, D., McEwen, B., \& Azmitia, E. Amnesia produced by electroconvulsive shock or cycloheximide: Conditions for recovery. Science, $1970,169,683-686$.

Quartermain, D.. McEwen, B., \& Azmitia, E. Recovery of memory following amnesia in the rat and the mouse. Journal of Comparative \& Physiological Psychology, 1972, 79,
360-379.
Sara, S. J. Recovery from hypoxia and ECS induced amnesia after a single exposure to the training environment. Physiology \& Behavior, 1973, 9, 85-89.

Springer, A., \& Miller, R. R. Retrieval failure induced by electroconvulsive shock: Reversal with dissimilar training and recovery agents. Science, $1972,177,628-630$

Zinkin, S., \& Miller, A. J. Recovery of memory after amnesia induced by electroconvulsive shock. Science, 1967, 155, 102-104.

(Received for publication May 21, 1973.)

\section{The effects of prolonged thwarting on instrumental response extinction*}

\author{
HOWARD GLAZER $\dagger$, JAW-SY CHEN \\ DEBERIE GOMEZ and ABRAM AMSEL
}

The University of Texas, Austin, Tex. 78712

To study the effects of prolonged frustration on extinction of a subsequently learned running response, one group of rats (CF) were subjected to a treatment in their individual home cages in which food was visible but unattainable for extended periods of time. A control group (NF) remained untreated. All Ss were then trained in a runway under conditions of continuous reinforcement followed by extinction. Both groups were then retrained in the runway with continuous reinforcement followed by a second extinction. In the second extinction, visible but unattainable food, rather than nonreward, was employed. Ss from Group CF extinguished faster and retraced more than did those from Group NF in the first extinction; in the second extinction, the differences were in the same direction but were not significant.

It is now a well-established finding that the introduction of an aversive event during the performance of an appetitively motivated instrumental response leads to a subsequent increase in the persistence of that response in the face of disruptive stimuli. Perhaps the best-known example of this phenomenon depends on the introduction of nonreward during the partial

\footnotetext{
*This research was supported by University Research Institute Grant SRF-435 from the University of Texas at Austin and by Grant GB-14990X from the National Science Foundation. Requests for reprints should be sent to Abram Amsel Department of Psychology, University of Texas at Austin, A ustin, Tex. $\mathbf{7 8 7 1 2}$.

tHoward Glazer is now at the Department of Psychology, The Rockefeller University, New York, N.Y. 10021.
}

reinforcement procedure; but aversive events other than nonreward have been shown to enhance resistance to extinction following their introduction during acquisition. These include goal blocking (Glazer \& Amsel, 1970), delay of reward (Rashotte \& Surridge, 1969), electric shocks (Brown \& Wagner, 1964), air blasts (Terris, German, \& Enzie, 1969), and loud tones (Amsel, Glazer, Lakey, McCuller, \& Wong, 1973). For purposes of the present experiment, the important procedural element these studies have in common is the introduction of brief aversive stimulation on some trials in the context of rewarded instrumental responding.

According to a persistence theory account of these and similar findings (Amsel, 1972), two competing response tendencies are set up in the organism, one related to the ongoing instrumental response, the other to a competing response elicited by the disruptive (aversive) stimulation. As long as the ongoing instrumental response is reinforced, even intermittently, the competition diminishes and the instrumental response becomes strong and persistent. The proposed mechanism for the conflict resolution and persistence is counterconditioning. In the special case of partial reinforcement, stimuli from anticipation of the aversive nonreward come to elicit the instrumental approach response.

The present experiment is a first attempt to reverse the operation of such a mechanism of persistence through prolonged periods of aversive stimulation in the absence of opportunity for counterconditioning such stimulation to approach. Introducing a piece of unattainable food to a hungry rat should set up a 